\title{
ASTEROIDS, COMETS, METEORS 1993
}

Edited by A. MILANI, M. DI MARTINO and A. CELLINO
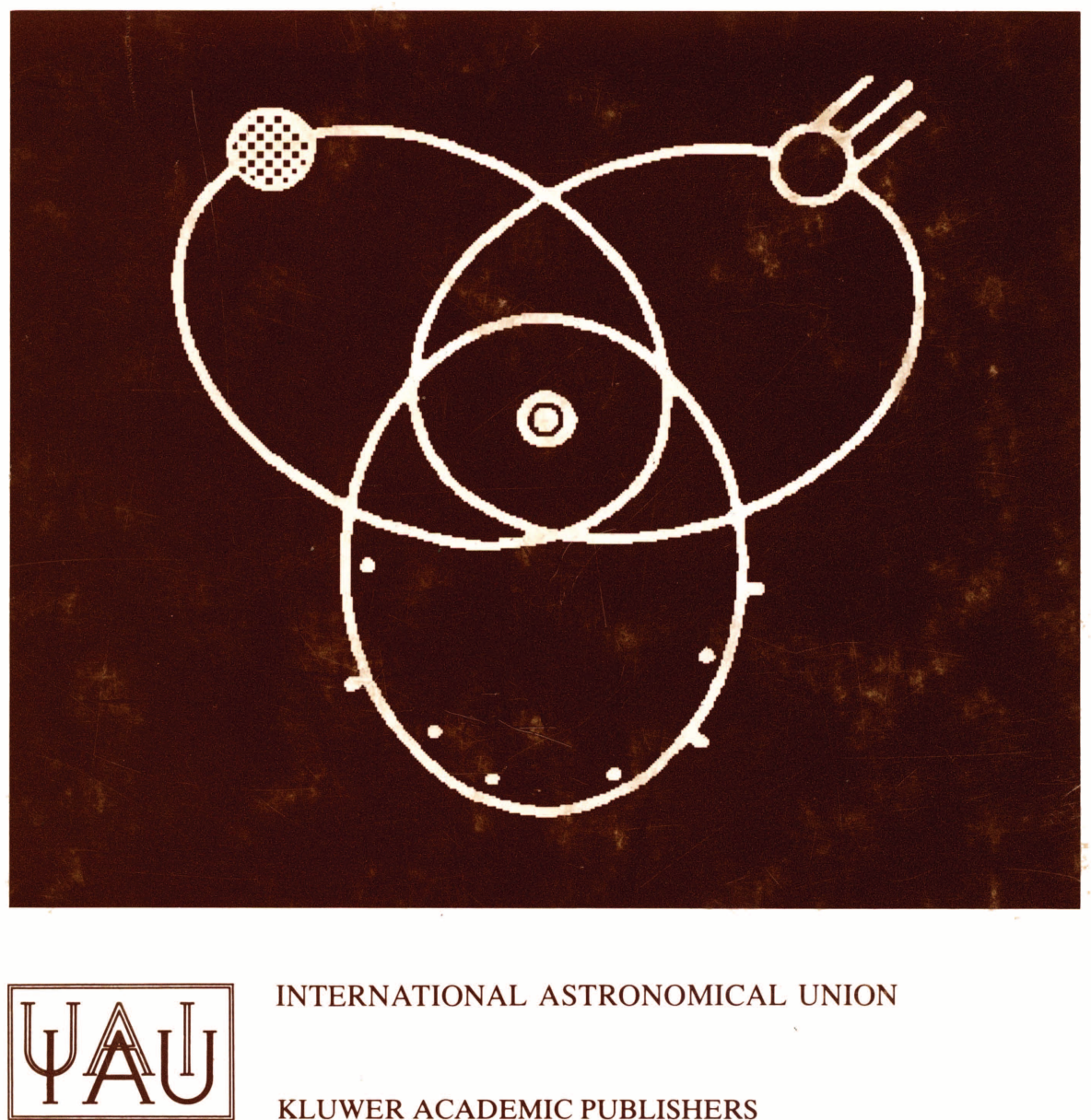

INTERNATIONAL ASTRONOMICAL UNION

KLUWER ACADEMIC PUBLISHERS 
ASTEROIDS, COMETS, METEORS 1993 


\title{
ASTEROIDS, COMETS, METEORS 1993
}

PROCEEDINGS OF THE 160TH SYMPOSIUM OF THE INTERNATIONAL ASTRONOMICAL UNION, HELD IN BELGIRATE, ITALY, JUNE 14-18, 1993

\author{
EDITED BY \\ A. MILANI \\ Dipartimento di Matematica, \\ Università di Pisa, Italy \\ and \\ M. DI MARTINO, A. CELLINO \\ Osservatorio Astronomico di Torino, \\ Pino Torinese, Italy
}

KLUWER ACADEMIC PUBLISHERS

DORDRECHT / BOSTON / LONDON

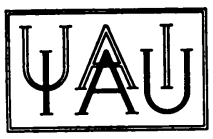


Library of Congress Cataloging-in-Publication Data

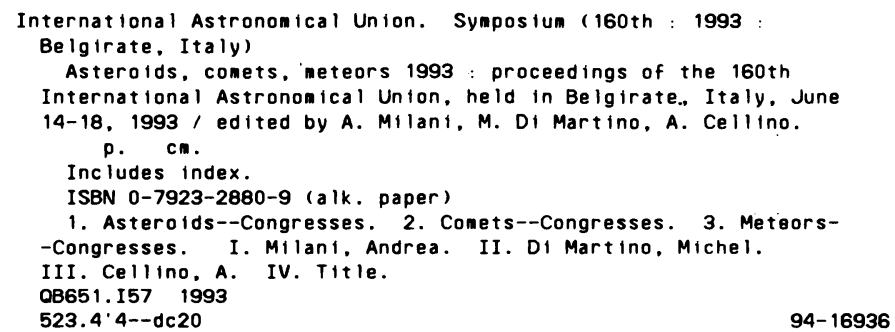

ISBN 0-7923-2880-9

Published on behalf of

the International Astronomical Union

by

Kluwer Academic Publishers, P.O. Box 17, 3300 AA Dordrecht, The Netherlands.

Kluwer Academic Publishers incorporates

the publishing programmes of

D. Reidel, Martinus Nijhoff, Dr W. Junk and MTP Press.

Sold and distributed in the U.S.A. and Canada

by Kluwer Academic Publishers,

101 Philip Drive, Norwell, MA 02061, U.S.A.

In all other countries, sold and distributed

by Kluwer Academic Publishers Group,

P.O. Box 322, 3300 AH Dordrecht, The Netherlands.

Printed on acid-free paper

\author{
All Rights Reserved \\ (C) 1994 International Astronomical Union
}

No part of the material protected by this copyright notice may be reproduced or utilized in any form or by any means, electronic or mechanical including photocopying, recording or by any information storage and retrieval system, without written permission from the publisher.

Printed in the Netherlands 


\section{TABLE OF CONTENTS}

INTRODUCTION ..............................................

SCIENTIFIC AND LOCAL ORGANIZING COMMITTEES ............... xii

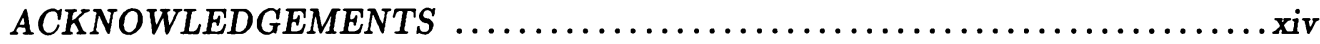
PHOTOGRAPH OF SYMPOSIUM PARTICIPANTS ................... LIST OF PARTICIPANTS ................................... xvii

\section{SEARCH PROGRAMS}

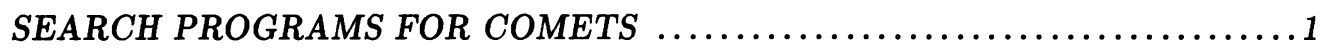
B.G. Marsden

COMPUTER AIDED NEAR EARTH OBJECT DETECTION .............17 J.V. Scotti

THE KUIPER BELT ....................................... 31

J. Luu

DENSITY OF METEOROIDS AND THEIR MASS INFLUX ON THE EARTH 45 P.B. Babadzhanov

\section{POPULATIONS OF SMALL BODIES}

ASTEROID ALBEDOS AND DIAMETERS ....................... 55 E.F. Tedesco

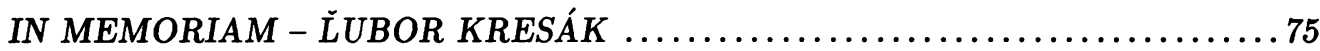

A. Carusi and G. Valsecchi

COMETS (EXISTING POPULATIONS) ..........................77

L. Kresák

THE COMET-ASTEROID TRANSITION:

RECENT TELESCOPIC OBSERVATIONS .......................95

L.A. McFadden

METEOROID STREAMS ......................................111

D. Steel

ZODIACAL DUST BANDS .................................127

S.F. Dermott, D.D. Durda, B.A.S. Gustafson, S. Jayaraman, J.C. Liou

and Y.L. Xu 
vi

\section{DYNAMICS}

ASTEROID PROPER ELEMENTS: THE BIG PICTURE 143 Z. Knežević and A. Milani

THE DYNAMICS OF THE TROJAN ASTEROIDS 159 A. Milani

KIRKWOOD GAPS AND RESONANT GROUPS 175

S. Ferraz-Mello

THE SECULAR RESONANCES IN THE SOLAR SYSTEM 189 Ch. Froeschlé and A. Morbidelli

METEORITE DELIVERY AND TRANSPORT .205 $P$. Farinella, Cl. Froeschlé and $R$. Gonczi DYNAMICS OF COMETS: RECENT DEVELOPMENTS AND NEW CHALLENGES .223 J.A. Fernández

A REVIEW OF COMETS AND NON GRAVITATIONAL FORCES 241 D.K. Yeomans

\section{PHYSICAL OBSERVATIONS AND MODELING}

ASTEROID SPECTROSCOPY AND MINERALOGY 255 T.H. Burbine and R.P. Binzel

COHERENT BACKSCATTERING BY SOLAR SYSTEM DUST

PARTICLES

K. Muinonen

COMETARY NUCLEI

H. Rickman

MOLECULAR ABUNDANCES IN COMETS

J. Crovisier

COMETS AS REFLECTION OF INTERSTELLAR MEDIUM CHEMISTRY

J.M. Greenberg and O.M. Shalabiea

METEOROID PROPERTIES FROM PHOTOGRAPHIC RECORDS

OF METEORS AND FIREBALLS 343

Z. Ceplecha 


\section{OBSERVATIONS FROM SPACE}

THE GALILEO ENCOUNTERS WITH GASPRA AND IDA .357 C.R. Chapman

DUST MEASUREMENTS IN THE OUTER SOLAR SYSTEM .367 E. Grün

THE ROSETTA MISSION TO PRIMITIVE BODIES OF THE SOLAR SYSTEM .381

Y. Langevin

\section{ORIGIN AND EVOLUTION}

ASTEROID FAMILIES .395

V. Zappalà and A. Cellino

COMET TAXONOMY AND EVOLUTION

D.G. Schleicher

SMALL BODIES AROUND OTHER STARS 429

B. Sicardy

FORMATION OF THE OUTER SOLAR SYSTEM BODIES:

COMETS AND PLANETESIMALS 443 M.E. Bailey

\section{DATA BASES}

THE ACM93 SMALL BODIES DATA BASES 461

IRAS MINOR PLANETS SURVEY 463 E.F. Tedesco

A COMPOSITE CATALOGUE OF ASTEROID PROPER ELEMENTS 467

A. Milani, E. Bowell, Z. Knežević, A. Lemaitre, A. Morbidelli, and $K$. Muinonen

THE UPPSALA ASTEROID DATA BASE .471

P. Magnusson, C.-I. Lagerkvist, M. Dahlgren, A. Erikson, M.A. Barucci,

I. Belskaya, and M.T. Capria

A PUBLIC-DOMAIN ASTEROID ORBIT DATA BASE 477

E. Bowell, K. Muinonen, and L.H. Wasserman 
viii

AN OVERVIEW OF DATASETS ON SMALL BODIES AVAILABLE THROUGH THE PLANETARY DATA SYSTEM AND SOARD . 483

D.R. Davis, M. A'Hearn, E. Grayzeck, M.V. Sykes, E.M. Alvarez del Castillo,

D. Tholen, and $K$. Garlow

MPC AND ICQ DATABASES 489

B.G. Marsden, D.W.E. Green, and G.V. Williams

THE UPPSALA COMET MAGNITUDE DATA BASE 495 L. Kamél

METEOROID ORBITS AVAILABLE FROM THE IAU METEOR DATA

CENTER

.497

B.A. Lindblad and D.I. Steel

LIST OF COLLABORATING AUTHORS

503 